\title{
Inconvenient Retail Depositors of the Euro Area Credit Institutions - Who Are They?
}

\author{
Katarzyna Kinga Kochaniak
}

\begin{abstract}
This paper presents the determinants of the Eurozone households' willingness to possess high value deposits, against the background of post-crisis funding stability regulations for the European Union (EU) credit institutions.

The EU Credit Institutions are required to improve the stability of their funding through household deposits' accumulation. However, new supervisory norms - Liquidity Coverage Ratio and Net Stable Funding Ratio - perceive the deposits above EUR 500,000 as less stable and discourage the entities to accept them. This solution may rise a question about the profiles of individuals who provide funding and inefficiently influence the reported liquidity of credit institutions.

The aim of this study is to identify the euro area models of households providing large deposits to credit institutions in 9 member states.

On the basis of logistic regression models certain supranational characteristics, which boost the probability of deposit possession (wealth and socio-demographic) are recognised.
\end{abstract}

The study is based on household-level data provided by the Eurosystem Household Finance and Consumption Survey.

Index Terms-High value household deposits, funding stability, credit institutions, liquidity standards.

\section{INTRODUCTION}

The European Union (EU) single, post-crisis regulations for credit institutions ${ }^{1}$ actively encourage a shift back to traditional sources of funding based on household deposits. Under the standards: Liquidity Coverage Ratio (LCR) and Net Stable Funding Ratio (NSFR) included in the package CRD IV/CRR (Directive 2013/36/EU [1]; Regulation (EU) No. 575/2013 [2]), the entities are required to prove the stability of their funding, leveraging an almost total potential of household deposits in the ratios' calculations. However, the new standards favour deposits with precise features, one of which is their value not exceeding the threshold of EUR 500,000 . According to the regulations, surpassing this limit makes deposits more vulnerable, i.e. less useful for the fulfilment of the funding requirements. Precise description of stable and less stable household deposits during periods of stress is presented in delegated act of the European

Manuscript received March 8, 2016; revised June 1, 2016. The paper presents the results of a study carried out under a research project financially supported by the National Science Centre in Poland (grant number: UMO-2013/11/D/HS4/04056). The analysis is based on data from the Eurosystem Household Finance and Consumption Survey.

K. K. Kochaniak is with Cracow University of Economics, Cracow, Poland (e-mail: katarzyna.kochaniak@uek.krakow.pl).

${ }^{1}$ Any institution that is either (1) an undertaking whose business is to receive deposits or other repayable funds from the public and to grant credit for its own account, or (2) an undertaking or any other legal person, other than those under (1), which issues means of payment in the form of electronic money.

\section{Commission (EC) [3].}

The aim of this paper is to identify the profiles of households who provide high value deposits ${ }^{2}$ for credit institutions in the euro area. It recognises the features boosting the probability of large deposit possession within the populations of 9 countries. The study is conducted on household-level data from the Eurosystem Household Finance and Consumption Survey (HFCS) ${ }^{3}$. Not all member states met the criteria to enter the study. Their participation was conditioned by the availability of data on households characterised by these deposits. This paper answers the following research question:

What are the supranational determinants of households' willingness ${ }^{4}$ to possess large deposits in the euro area countries?

The following hypothesis is tested:

High value deposits are the attribute of affluent households characterised by specific socio-demographic characteristics. However, their occurrence is not uniform across the analysed member states of the euro area.

The paper is organized as follows: (II) related literature; (III) description of research methods and variables applied in the study; (IV) the results of empirical analysis; (V) conclusions.

\section{RELATED LiterATURE}

The nature and determinants of high value household deposits appear as new issues in the literature due to the brief history of the single EU regulatory requirements on the funding stability of credit institutions. Currently, they emerge as interesting topics against the turbulent economic and financial background of the Eurozone.

The overall household deposits have been analysed in a number of studies focused on aspects ranging from their significance for banks' funding [4]-[7] to their position in the financial asset portfolios of individuals [8]-[11]. Some of them analyse the deposits against the background of the financial crisis. The worldwide literature discusses, among others, the linkages between national deposit guarantee schemes and investors' perception of risk [12]-[13]. Some studies verify relationships between deposit withdrawals and the occurrence of crisis [14], changes in market interest rates [15]-[16], stresses on commercial paper markets [17]-[18], or loan availability [17], [19].

${ }^{2}$ In this paper "high value deposits" are also named "large deposits".

${ }^{3}$ Database of restricted access. In individual countries, the first wave of the survey took place in: 2008/2009 in Spain; 2010 in Belgium, Finland, France, Italy; 2010/2011 in Austria, Cyprus, Germany, Luxembourg.

${ }^{4}$ This willingness is associated household propensity or ability to possess high value deposits. 
A vast literature undertakes the problem of household saving motives and household behaviour affecting investment decisions, including the possession of deposits. Some of them refer directly to motives [16], [20]-[21] and households' ability or propensity to save [22]-[23], while others are focussed on determinants of saving decisions, e.g. socio-demographic [24]-[25] institutional [25]-[27] or macroeconomic [25], [28].

\section{DATA AND METHODOLOGY}

The study was conducted for 9 euro area member states:

Austria, Belgium, Cyprus, Finland, France, Germany, Italy, Luxembourg, and Spain. In these countries, the samples of households surveyed contained the observations of high value deposits, which exceeded a minimum floor adopted in the analysis ${ }^{5}$.

The study was based on quantitative and qualitative Eurosystem HFCS household-level data [29]. It should be noted that in case of households possessing high value deposits the database did not provide information on whether the sums exceeding EUR 500,000 were located in one or more credit institutions. The sets of variables were organized as follows:

1) Quantitative, describing the household's size $(\mathrm{N})$ : number of members 16+ (NM16+);

2) Quantitative, describing the household's wealth (W): gross income (WGI); net wealth ${ }^{6}(\mathrm{WNW})$; high-value deposits (WHD); total value of real assets (WRA), e.g., real estate, vehicles and valuables; total value of financial assets without deposits (WFA);

3) Quantitative, describing the reference person's age (A);

4) Qualitative, describing the reference person's:

- the highest level of education completed (E): tertiary (ETR); upper secondary (EUS); lower secondary (ELS); primary or below (EPR);

- marital status (M): married (MAR); single/never married (MSI); consensual union on legal basis (MCU); widowed (MWI); divorced (MDI);

- labour status (L): doing regular work for pay/self-employed/working in family business (LSW); on sick, leave maternity or other type of leave (LSL); unemployed (LSU); student or pupil or unpaid intern (LSS); retiree or early retiree (LSR); permanently disabled (LSD); compulsory military service or equivalent social service (LSM); fulfilling domestic tasks (LST); other - not working for pay (LSO);

- gender (G): male (GMA); female (GFE);

5) Qualitative, describing the household's country of residence (C): Austria (AT); Belgium (BE); Cyprus (CY); Finland (FI); France (FR); Germany (DE); Italy (IT); Luxembourg (LU); Spain (ES).

The verification of supranational determinants of household propensity/ability to possess large deposits in the group of the euro area countries required the application of above variables into the logit model, described by the

\footnotetext{
${ }^{5}$ The euro area member states with national samples of households containing at least 9 cases of households with large deposits became incorporated in this study.

${ }^{6}$ Net wealth is defined as the difference between total (gross) assets and total liabilities. Total assets consist of real assets and financial assets.
}

following formula:

$$
y_{i}^{*}=\beta_{0}+\sum_{j=1}^{k} \beta_{j} x_{i j}+\varepsilon_{i}
$$

where: $y_{i}^{*}$ - latent variable; $x_{i j}$ - explanatory variables $(i=1$, $2, \ldots, n ; j=1,2, \ldots, k) ; \beta_{j}$ - regression parameters $\left(\beta_{0}-\right.$ constant); $\boldsymbol{\varepsilon}_{i}$ - random component.

All observations of high value deposits enabled to form a dummy $Y$ which represented the fact that households owned high value deposits ( $Y=1$ when a household declared a large deposit, otherwise $Y=0$ ). Thus, in the logit model the variable $y_{i}^{*}$ could be defined as household propensity/ability to possess a deposit exceeding EUR 500,000 [30] or the probability of a high value deposit possession by a household, which depends on certain factors [31].

The Eurosystem HFCS included 265 households with large deposits in the group of analysed countries. The significant difference between that number and the number of remaining households (not possessing such deposits) prompted the need to balance the sample [30]. As a result, a random subset of a further 265 households without large deposits was taken. Thus, the final sample consisted of 530 households and was considered in the analysis.

Some of the quantitative variables were converted into categorical [32], i.e.: net wealth (WNW), gross income (WGI), total real assets (WRA), total financial assets without deposits (WFA), and age of reference person (A). The high diversity of these features resulted in their division into 3 categories: low level, medium level and high level. The boundaries of the assignment of characteristics to a certain category were determined by the values of quantile $0.33\left(q_{0.33}\right)$ and quantile $0.66\left(q_{0.66}\right)$. Thus, the levels were defined as follows (Table I):

1) low level of the feature: lower then $q_{0,33}$;

2) medium level of the feature: from $q_{0,33}$ to $q_{0,66}$;

3) high level of the feature: above $q_{0,66}$.

TABLE I: NuMERICAL CHARACTERISTICS OF HOUSEHOLdS' SELECTED

\begin{tabular}{crr}
\multicolumn{3}{c}{ FEATURES (IN EUR) } \\
\hline Variable & $q_{0,33}$ & $q_{0,66}$ \\
\hline WNW & 268,992 & $2,008,625$ \\
WGI & 38,100 & 97,100 \\
WRA & 245,000 & 979,300 \\
WFA & 1,320 & 139,444 \\
\hline Source: own calculations derived from the Eurosystem HFCS data
\end{tabular}

Table I shows that variables for $33 \%$ of the Eurozone households depicted values not exceeding the quotations for $q_{0,33}$, while for the rest of households $(67 \%)$ - at least these sums. The quantile $q_{0,66}$ means that the characteristics of $66 \%$ of the households represented the values up to the pointed level and the remaining 34\% of households - at least these sums. In the next step, the categorical variables were converted into dummies, which were applied in the logit model. They referred to the low and high levels of the characteristics. The medium level became the basis for comparison. As a consequence, the net wealth (WNW) was converted into the following:

1) WNW LOW with the value of 1 when WNW < EUR 268,992 and 0 in all other cases; 
2) WNW MEDIUM with the value of 1 when EUR 268,992 $\leq \mathrm{WNW} \leq \mathrm{EUR} 2,008,625$ and 0 in all other cases;

3) WNW HIGH with the value of 1 when WNW > EUR 2,008,625 and 0 in all other cases.

The same was applied to the rest of the variables (WGI, WRA, WFA). In case of the age of reference person (A), the variable $A$ LOW took the value of 1 when $A \leq 50$ years old and 0 in all other cases; A MEDIUM took the value of 1 when 50 years old $<\mathrm{A} \leq 65$ years old in all other cases; A HIGH took the value of 1 when $A>65$ years old and 0 in all other cases.

Parameter estimates from the multiple regression model (explanatory variables were selected on the basis of stepwise regression) were used as initial values of parameters in logit model.

\section{RESULTS OF EMPIRICAL ANALYSIS}

The sets of household features influencing the propensity or ability to possess a high value deposit can be interpreted as supranational sets affecting the probability of large deposit possession by a household in the analysed area [31].

The study implemented a logistic regression model in 4 versions, in which the proposed factors describing the probability of high value deposit possession by a household were as follows:

1) WNW LOW, WNW HIGH - emphasizing the importance of the household's net wealth;

2) WNW LOW, WNW HIGH, WGI LOW, WGI HIGH, A LOW, AT, BE, CY, ES, FI, FR, IT, LU - comprising variables denoting net wealth and its important driver gross income, as well as low age of reference person and country affiliation $^{7}$;

3) WRA LOW, WRA HIGH, WFA LOW, WFA HIGH, A LOW, A HIGH, AT, BE, CY, ES, FI, FR, IT, LU modification of version 2, with the reference person's age, country of residence ${ }^{8}$ and the main types of household assets (real assets and financial assets without deposits) instead of net wealth and gross income;

4) NM16+, ETR, MAR, GMA, LSR, A LOW, A HIGH, AT, BE, CY, ES, FI, FR, IT, LU - denoting to the household's socio-demographic features and its country of residence ${ }^{9}$.

The first version of the logit model seemed the simplest. It tested the influence of net wealth on the probability of large deposit occurrence in a household. The WNW HIGH appeared as a statistically significant explanatory variable (Table II). Thus the propensity or ability to possess a large deposit by a household was increased when its net wealth was classified at the highest range of its values. This proved that a lifestyle strongly focussed on asset collection but not on consumption or living in debt was the favoured analysed propensity. It can also be concluded that high value deposits were an attribute of the most affluent households.

The odds ratio ${ }^{10}$ confirmed that the classification of households in the analysed category was more precise than a

\footnotetext{
${ }^{7}$ Germany was the basis for comparison.

${ }^{8}$ Ibidem.

${ }^{9}$ Ibidem.

${ }^{10}$ The odds ratio is defined as correctly classified cases in relation to incorrectly classified cases, with a given vector $x_{i}$ of explanatory variables.
}

random selection (the probability of carrying out a correct classification of households on the basis of this model was 69.31 times higher than an incorrect classification). More than $80 \%$ of households were properly classified. The likelihood ratio (LR) Chi-Square test confirmed the significant influence of the considered variable on household propensity or ability to possess a high value deposit. Thus, it rejected the hypothesis of the absence of such an effect.

The second version of the logit model used a whole set of potential (proposed) explanatory variables. According to the results, the propensity or ability to possess high value deposits was weaker in households with gross income and net wealth classified as low in comparison with households characterised by medium levels of those features. Also, the young age of reference persons appeared as a factor which significantly lowered the probability of large deposit possession, as opposed to middle age and old age. High net wealth $^{11}$, as well as high gross income were the characteristics which positively influenced the chance of the occurrence of analysed willingness. Thus, this version confirmed the conclusion of the former one. Moreover, assuming the same levels of the above features in the Eurozone, large deposits appeared more frequently in Austrian, Belgian, and Spanish households than in households from other countries. On the basis of the above criteria, it can be stated that the strongest propensity/ability to possess high value deposits appeared in the following model of a household: the wealthiest, residing in Austria, Belgium or Spain, with a reference person aged 51 years and over. The results of version 2 of the logit model are presented in Table III.

\begin{tabular}{lcccc}
\multicolumn{5}{l}{ TABLE II: SUMMARY OF LOGISTIC REGRESSION (VERSION 1) } \\
\hline Specification & $B$ & $S E B$ & $t(517)$ & $p$-value \\
\hline Constant & -1.0312 & 0.1214 & -8.4917 & 0.0000 \\
WNW & 4.2386 & 0.4043 & 10.4848 & 0.0000 \\
\hline
\end{tabular}

Odds ratio $=69.31$; correctly classified households $81.32 \%$; chi-square $(11)=272.34 ; p<0.0000$

$\overline{\text { Source: own calculations derived from the Eurosystem HFCS data. }}$

TABLE III: SUMMARY OF LOGISTIC REGRESSION (VERSION 2)

\begin{tabular}{lrrrr}
\hline Specification & \multicolumn{1}{c}{$B$} & \multicolumn{1}{l}{$S E B$} & \multicolumn{1}{l}{$t(517)$} & $p$-value \\
\hline Constant & -0.0767 & 0.2754 & -0.2787 & 0.7806 \\
WNW HIGH & 2.4103 & 0.4481 & 5.3788 & 0.0000 \\
WNW LOW & -27.6137 & 0.5530 & -0.0050 & 0.9960 \\
WGI HIGH & 0.8041 & 0.3853 & 2.0869 & 0.0374 \\
WGI LOW & -1.3380 & 0.4250 & -3.1485 & 0.0017 \\
A LOW & -1.3665 & 0.3963 & -3.4483 & 0.0006 \\
AT & 3.0382 & 1.2213 & 2.4877 & 0.0132 \\
BE & 2.1583 & 0.6625 & 3.2576 & 0.0012 \\
ES & 1.5464 & 0.4118 & 3.7554 & 0.0002 \\
\hline
\end{tabular}

Odds ratio $=61.63$; correctly classified households $88.68 \%$; chi-square $(8)=482.67 ; p<0.0000$

Source: own calculations derived from the Eurosystem HFCS data.

In this version the odds ratio confirmed better classification of households than a random one. Almost $90 \%$ of households were correctly classified. The likelihood ratio

${ }^{11}$ From the variables describing household finance, this one most strongly influenced the chance of having a high-value deposit. 
(LR) Chi-Square test confirmed the significant influence of a considered set of variables on household propensity or ability to possess a high value deposit and rejected the hypothesis of the absence of such effects.

The third version of the logit model did not contain the whole set of proposed explanatory variables. Only the following appeared as statistically significant: WRA HIGH, WRA LOW, WFA HIGH, A LOW, AT, BE, ES. According to the results presented in Table IV, certain countries of residence (the same as in the second version) had a positive impact on having a high value deposit. This means that the chance of a large deposit possession appeared greater there in comparison with the other member states, assuming the constancy of other independent variables. The same could be concluded for the variables WRA HIGH and WFA HIGH ${ }^{12}$. The propensity or ability to have a high value deposit increased when a household was supplied with real and financial assets with the values from the highest range. Conversely, if real assets did not exceed EUR 245,000, the chance of having a large deposit by a household was lower then in the households constituting the basis for comparison. Among the explanatory variables there was also A LOW, which revealed that the propensity/ability to possess a high value deposit was lower among young reference persons than in the other age groups. All the above shape the model of a household for which the probability of having a large deposit was the greatest in the analysed set of countries. It was characterised by the values of real and financial assets from the highest ranges, as well as the reference person of at least 51 years old, residing in Austria, Belgium or Spain.

\begin{tabular}{lrrrr}
\multicolumn{5}{c}{ TABLE IV: SUMMARY OF LOGISTIC REGRESSION (VERSION 3) } \\
\hline Specification & \multicolumn{1}{c}{ B } & \multicolumn{1}{c}{$t(517)$} & $p$-value \\
& & & \\
\hline Constant & -0.8077 & 0.2463 & -3.2798 & 0.0011 \\
WRA HIGH & 1.9047 & 0.3499 & 5.4434 & 0.0000 \\
WRA LOW & -1.5571 & 0.3432 & -4.5367 & 0.0000 \\
WFA HIGH & 1.9627 & 0.3263 & 6.0149 & 0.0000 \\
A LOW & -1.4526 & 0.3345 & -4.3426 & 0.0000 \\
AT & 1.5036 & 0.6419 & 2.3425 & 0.0195 \\
BE & 1.8107 & 0.5309 & 3.4104 & 0.0007 \\
ES & 1.2556 & 0.3292 & 3.8140 & 0.0002 \\
\hline \multicolumn{5}{c}{ Odds ratio=49.39; correctly classified households $87.52 \% ;$} \\
\multicolumn{5}{c}{ chi-square (7) $=379.25 ; p<0.0000$} \\
\hline
\end{tabular}

Source: own calculations derived from the Eurosystem HFCS data

The odds ratio indicated, as in the former versions, that better results were obtained from households which had been classified than from those randomly classified. The probability of carrying out a correct classification of households on the basis of this model was 49 times higher than an incorrect one. Almost $90 \%$ of households were classified properly. The likelihood ratio (LR) Chi-Square test confirmed the significant influence of a presented set of variables on household propensity/ability to possess a high value deposit and rejected the hypothesis of the absence of such an effect. Therefore, it can be concluded that all

\footnotetext{
${ }^{12}$ These variables most strongly affected the chance of having a large deposit by a household.
}

household features implied in the model - specified assets of a particular range of values, low age of reference person and exact countries of residence - had a significant impact on the propensity or ability of a household to possess large deposit in an analysed area.

The fourth version of the model was focused on the impact of socio-demographic features of a household on its willingness to hold a large deposit (Table V). From the set of potential explanatory variables, the following appeared as statistically significant: NM16+, ETR, LSR, GMA, A LOW, A HIGH, AT, BE, CY, ES, FR, LU. It should be noted that the dummies indicating the above countries of residence had a positive impact on the holding of a high value deposit by a household ${ }^{13}$. This means that there was a greater likelihood of possessing a large deposit than in Finland, Germany, and Italy. The probability of high deposit occurrence was boosted by an increase in the number of household members who were at least 16 years old. This was due to a greater chance of a higher number of working members. The ability or propensity to possess a high value deposit also increased with male reference person aged 65 years and over. Conversely, in a household with a young reference person the probability of large deposit occurrence was lower then in a household with a reference person at middle age. A positive impact was also obtained for completed tertiary education by respondents ${ }^{14}$. Among households with retired reference persons the propensity or ability to possess the analysed type of deposits was lower than in households with reference persons of other labour statuses. According to the outcomes, high value deposits became an attribute of a household with a greater number of adult or almost adult members, represented by well-educated, older, but not on retirement male respondent.

TABLE V: SUMMARY OF LOGISTIC REGRESSION (VERSION 4)

\begin{tabular}{lclrl}
\hline \multicolumn{1}{c}{ Specification } & $B$ & SE B & $t(517)$ & $p$-value \\
\hline Constant & -2.7030 & 0.4882 & -5.5377 & 0.0000 \\
A LOW & -2.2266 & 0.3507 & -6.3495 & 0.0000 \\
A HIGH & 0.9877 & 0.3634 & 2.7179 & 0.0068 \\
NM16+ & 0.5087 & 0.1554 & 3.2719 & 0.0011 \\
ETR & 1.6854 & 0.2493 & 6.7602 & 0.0000 \\
LSR & -0.9675 & 0.3664 & -2.6401 & 0.0085 \\
GMA & 0.6954 & 0.2469 & 2.8121 & 0.0051 \\
AT & 2.3697 & 0.6077 & 0.8997 & 0.0001 \\
BE & 1.7913 & 0.4772 & 3.7534 & 0.0002 \\
CY & 1.4646 & 0.3345 & 1.9873 & 0.0473 \\
ES & 1.9893 & 0.3242 & 6.1346 & 0.0000 \\
FR & 0.6655 & 0.3137 & 2.1215 & 0.0343 \\
LU & 2.1608 & 0.6735 & 3.2084 & 0.0014 \\
\hline
\end{tabular}

Odds ratio $=16.00$; correctly classified households $80.00 \%$; chi-square

$(12)=272.41 ; p<0.0000$

Source: own calculations derived from the Eurosystem HFCS data

The odds ratio confirmed better results from classified households than from a random one. The probability of

\footnotetext{
${ }^{13}$ In relation to the countries forming the basis for comparison.

${ }^{14}$ From the variables describing socio-demographic features of households, this one appeared as most strongly boosting the chance of having a high-value deposit.
} 
carrying out a correct classification of households on the basis of this model was 16 times higher than an incorrect classification. There were $80 \%$ of households properly classified. The likelihood ratio (LR) Chi-Square test revealed a significant influence of all considered variables regarding high value deposit possession, thus rejecting the hypothesis of the absence of such an effect. In conclusion, the socio-demographic features which were implied in this version had a significant influence on the euro area households' willingness to possess large deposits.

\section{CONCLUSIONS}

The lessons learnt from the most recent financial crisis have emphasised the importance of household deposits for the resilience of credit institutions to liquidity shocks. However, the modified EU regulations perceive deposits exceeding EUR 500,000 as less stable.

The study identified common sets of features fostering the likelihood of having a large deposit by a household in the euro area. Thus, it recognised the profiles of households whose deposits cannot be effectively utilized by credit institutions as a source of stable funding. All versions of the logit model described the analysed problem correctly, but from different perspectives. They clearly showed the importance of household wealth (financial and real assets, as well as gross income), as well as socio-demographic characteristics (number of households, age of reference person, level of education completed and gender) for the occurrence of analysed phenomenon.

The wealth and its components appeared as features of major importance, leading to the conclusion that a life style strongly focussed on the accumulation of financial and real assets was responsible for the occurrence of large deposits.

The tendency to possess high value deposits was relatively low among households with young reference persons. However, the need to possess large deposits in the other age groups might be caused by decreasing incomes in later life.

The logit model in versions 2-4 emphasised stronger ability or propensity of households in Austria, Belgium, and Spain to accumulate large deposits.

The last version of the model revealed the profile of a household, described by its socio-demographic features (greater number of adult or almost adult members; above 65 years old but still working, well educated, male respondent) which fostered the ability or propensity of a household to have a high value deposit.

The results confirm the existence of common profiles of households possessing large deposits in the analysed area. However, in some countries their occurrence is assessed as more frequent. Assuming that the post-crisis funding regulations are accurate guidelines, these depositors can be perceived by credit institutions as the providers of lower quality funding. However, the adopted threshold is rather conjectural than based on the results of empirical analysis. Thus, future monitoring of deposits withdrawn by the households with presented features can be useful in the assessment of the correctness of the current EU regulatory stance on the nature of large deposits.

To conclude, the results acquired from the study proved the hypothesis.

\section{REFERENCES}

[1] Directive 2013/36/EU of the European Parliament and of the Council of 26 June 2013 in access to the activity of credit institutions and the prudential supervision of credit institutions and investment firms, amending Directive 2002/87/EC and repealing Directives 2006/48/EC and 2006/49/EC, OJ L 176, 27.06.2013.

[2] Regulation (EU) No 575/2013 of the European Parliament and of the Council of 26 June 2013 on prudential requirements on credit institutions and investment firms and amending Regulation (EU) No 648/2012, OJ L 176, 27.06.2013.

[3] Commission Delegated Regulation (EU) 2015/61 of 10 October 2014 to supplement Regulation (EU) No 575/2013 of the European Parliament and the Council with regard to liquidity coverage requirement for Credit Institutions, OJ L 11, 17.01. 2015.

[4] C. Borio, "Ten propositions about liquidity crises," BIS Working Paper, 293, pp. 1-21, 2009.

[5] A. Deaton, "Saving and liquidity constraints," NBER Working Paper, 3196, pp. 1-41, 1989.

[6] D. W. Diamond and R.G. Rajan, "Banks and liquidity," American Economic Review, vol. 91, no. 2, pp. 422-425, 2001.

[7] R. Huang and L. Ratnovski, "The dark side of bank wholesale funding," Journal of Financial Intermediation, vol. 20, pp. 248-263, 2011.

[8] P. D. Caju, "Structure and distribution of household wealth: An analysis based on the HFCS," National Bank of Belgium Economic Review, vol. 9, pp. 41-62, 2013.

[9] ECB, "The Eurosystem Household Finance and Consumption Survey results from the first wave," ECB Statistics Paper Series, 2/April, pp. $1-112,2013$

[10] K. Kochaniak, "The stability of household deposits in financial and economic crises of the Euro Area member states - regulations vs. reality," Bank \& Credit, vol. 46, no. 5, pp. 487-522, 2015.

[11] F. Teppa, A. Porpiglia, M. Ziegelmeyer, J. Le Blanc, and J. Zhu, "Household saving behaviour and credit constraints in the euro area," ECB Working Paper, pp. 1-62, 2015.

[12] V. Acharya and N. Mora, "A crisis of banks as liquidity providers," The Journal of Finance, vol. 70, no. 1, pp. 1-43, 2015.

[13] M. Brown, B. Guin, and S. Morkoetter, "Deposit withdrawals from distressed commercial banks," Swiss Institute of Banking and Finance Working Papers on Finance, vol. 19, pp. 1-33, 2013.

[14] M. Cussen, B. O'Leary, and D. Smith, "The impact of the financial turmoil on households: A cross country comparison," Central Bank of Ireland Quarterly Bulletin, 02 / April, pp. 78-98, 2012.

[15] V. Acharya and N. Mora, "Are banks passive liquidity backstops? Deposit rates and flows during the 2007-2009 crisis," NBER Working Paper, pp. 1-64, 2012.

[16] S. Bouyon, "A review of policy options for monitoring household saving," European Credit Research Institute, vol. 16, pp. 1-24, 2014.

[17] E. Gatev, T. Schuermann, and P. Strahan, "Managing bank liquidity risk: how deposit-loan synergies vary with market conditions," Review of Financial Studies, vol. 22, pp. 995-1020, 2009.

[18] G. Pennacchi, "Deposit insurance, bank regulation, and financial system risks," Journal of Monetary Economics, vol. 53, pp. 1-30, 2006.

[19] V. Acharya, H. Almeida, and M. Campello, "Aggregate risk and the choice between cash and lines of credit," The Journal of Finance, vol. 68, pp. 2059-2116, 2013.

[20] C. G. Boeree. (July 2010). Abraham Maslow and Theories of Personality. [Online]. Available: http://www.social-psychological.de/do/pt_maslow.pdf

[21] J. J. Xiao and F. E. Noring, "Perceived saving motives and hierarchical financial needs," Financial Counseling and Planning, vol. 5, pp. 25-44, 1994.

[22] G. Katona, Psychological Analysis of Economic Behavior, New York: McGraw-Hill, 1951.

[23] R. H. Thaler and H. M. Shefrin, "An economic theory of self-control," Journal of Political Economy, vol. 89, no. 2, pp. 392-406, 1981.

[24] S. A. Devaney, S. T. Anong, and S. E. Whirl, "Household saving motives," The Journal of Consumer Affairs, vol. 41, no. 1, pp. 174-185, 2007.

[25] T. Jappelli and M. Pagano, "The determinants of saving: lessons from Italy," Inter American Development Bank Office of the Chief Economist Research Network Working Paper, R-313, pp. 1-32, 1997.

[26] S. G. Beverly and M. Sherraden, "Institutional determinants of saving: implications for low-income households and public policy," Journal of Socio-Economics, vol. 28, no. 4, pp. 457-473, 1999.

[27] T. Callen and C. Thimann, "Empirical determinants of household saving: Evidence from OECD countries," IMF Working Paper, WP/97/181, pp. 1-26, 1997. 
[28] B. B. Aghevli, J. M. Boughton, P. J. Montiel, D. Villanueva, and G. Woglom, "The role of national saving in the world economy: recent trends and prospects," IMF Occasional Paper, vol. 67, pp. 11-15, 1990.

[29] ECB, HFCS Country Surveys Metadata Information, Frankfurt am Main: European Central Bank, 2013.

[30] G. S. Maddala, Econometrics, Warsaw: Wydawnictwo Naukowe PWN, 2014.

[31] P. Ulman, Sytuacja ekonomiczna osób niepetnosprawnych $i$ ich gospodarstw domowych w Polsce, Cracow: Wydawnictwo Uniwersytetu Ekonomicznego w Krakowie, 2011.

[32] B. Podolec, P. Ulman, and P. A. Wałęga, Aktywnosc ekonomiczna a sytuacja materialna gospodarstw domowych, Cracow: Wydawnictwo Uniwersytetu Ekonomicznego w Krakowie, 2008.

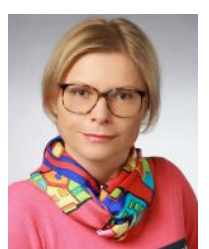

Katarzyna K. Kochaniak got the Ph.D. in economics from Cracow University of Economics, Poland in 2009. She is an Assistant Professor in the Department of Finance, Cracow University of Economics, Poland. 